\title{
PATRIMÔNIO, DIVERSIDADE CULTURAL E EDUCAÇÃO ESCOLAR: A EDUCAÇÃO PATRIMONIAL NO PROGRAMA MAIS EDUCAÇÃO
}

\author{
Rodrigo Manoel Dias da SILVA ${ }^{1}$ \\ Márcia Amélia Cletes de MORAES ${ }^{2}$
}

RESUMO: O presente artigo visa compreender as relações entre educação patrimonial e diversidade cultural nas políticas educacionais brasileiras, com ênfase na análise de documentos ministeriais que inserem a educação patrimonial como temática no Programa Mais Educação. Os autores analisam dois deslocamentos na produção dos sentidos atribuídos historicamente à educação patrimonial e suas relações com os processos de escolarização contemporâneos.

PALAVRAS-CHAVE: Educação patrimonial. Diversidade cultural. Política educacional.

\section{INTRODUÇÃO}

Historicamente, diversidade cultural foi um tema periférico na agenda das políticas para a escolarização na América Latina. Diversas reformas estatais para o setor foram planejadas e implantadas, sobretudo na segunda metade do século XX, entretanto a temática não foi considerada nestas elaborações ou, quando inserida na pauta nacional, oferecia pouco impacto sobre os sistemas educacionais (ZAMBRANO, 2000). De acordo com Antônio Bolívar (2004), o modelo escolar implantado na América Latina erigiu-se a partir de uma "mestiçagem uniformizadora", o qual atribuía à escola funções assimilacionistas e de caráter institucional. O caráter cultural dos projetos de escolarização latino-americanos centrava-se em um processo de "enquadramento da memória" (POLLAK, 1989), constituído pela supremacia das memórias nacionais, pelos objetivos de elevação cultural das camadas economicamente mais pobres e pela salvaguarda da memória e do patrimônio de origem lusitana.

Assim, a educação escolar fez parte de um longo processo de enculturação (MARTÍN-BARBERO, 2009). No Brasil, caracterizações históricas e sociológicas da Era Vargas explicitam igualmente os empenhos realizados pela centralização estatal e pela uniformização da identidade nacional (SCHWARTZMAN; BONEMY; COSTA, 2000).

${ }^{1}$ UNISINOS - Universidade do Vale do Rio dos Sinos. Pós-Graduação em Educação. São Leopoldo - RS - Brasil. 93022000 - rodrigoddsilva@ hotmail.com

${ }^{2}$ Especialista em História e Cultura Indígena e Afro-brasileira. ULBRA - Universidade Luterana do Brasil. Canoas - RS - Brasil. 92425-900. Escola Adventista de Erechim. Erechim - RS - Brasil. 99700000 - m.a.mel@ibest.com.br 
A educação patrimonial no Brasil, enquanto modalidade formativa voltada para a conservação do patrimônio histórico, cultural e artístico, surge no começo do século XX em decorrência da criação do Serviço do Patrimônio Histórico e Artístico Nacional. Embora sua denominação remeta à década de 1980, práticas de conscientização e defesa do patrimônio nacional estavam na agenda de Mário de Andrade e outros ilustres intelectuais brasileiros. A relação entre educação e patrimônio orientou-se pela construção imaginária do nacional (CANCLINI, 1994), reafirmando representações eurocêntricas de patrimônio, sobretudo a partir dos vestígios materiais remanescentes do período colonial.

O início do século XXI nos trouxe novos elementos para a discussão sobre educação patrimonial. O reconhecimento da diversidade cultural passa a compor um conjunto de novas temáticas que têm problematizado às políticas para a escolarização na América Latina e no Brasil (ZAMBRANO, 2000; BOLÍVAR, 2004; SILVA, 2010; DOMÍNGUEZ; 2012; 2013; CANDAU, 2014), mobilizado pela ideia de democratização cultural (SILVA, 2013).

Diante deste cenário, o presente artigo versa sobre as relações entre a educação patrimonial e a diversidade cultural brasileira, com ênfase nas iniciativas desenvolvidas a partir da inserção da educação patrimonial como temática do Programa Mais Educação, do Ministério da Educação. Então, em sentido específico, problematizamos como tal diversidade tem sido incorporada no Programa Mais Educação, em particular a partir da inserção da educação patrimonial como temática formativa nesta política.

\section{PATRIMÔNIO E EDUCAÇÃO NO BRASIL: UMA LEITURA HISTÓRICA}

A ideia de patrimônio se originou na experiência histórica francesa no período pós-revolucionário, onde o governo deveria proteger e zelar pelos monumentos que representavam e significavam a história do Estado. A República Francesa, de certo modo, inventou a ideia de patrimônio, com ênfase na produção da unidade nacional, a produção de uma "identidade francesa", onde a escola foi uma instituição fundamental. Como escreveu Pollak (1989), podemos pensar que ocorreu um enquadramento da memória, pois o patrimônio fortalecia a história e a memória oficiais (grandes nomes, datas cívicas, símbolos da pátria, etc.). Em outra perspectiva, patrimônio também expressa a solidariedade entre indivíduos e grupos que compartilham bens, práticas e 
identificações, uma vez que contribui na coesão social ou na "cumplicidade social" (CANCLINI, 1994).

No Brasil, durante o Estado Novo, foi promulgado o Decreto-Lei no 25/1937 que define patrimônio cultural como um “[...] conjunto dos bens móveis e imóveis existentes no país cuja conservação seja de interesse público que por sua vinculação a fatores memoráveis, que pelo seu excepcional valor arqueológico ou etnográfico, bibliográfico ou artístico." O mesmo ato criou o Serviço de Patrimônio Histórico e Artístico Nacional (SPHAN), influenciado por Mário de Andrade e outros modernistas.

Desde a criação do SPHAN, as políticas para o patrimônio no Brasil estiveram voltadas para a produção da unidade nacional, a partir de uma identidade nacional. Em meio à Era Vargas, predominavam objetivos nacionalistas, os quais estavam na pauta de diversos intelectuais, sobretudo Mário de Andrade. Estas ações estavam centradas na produção de uma cultura homogênea e na elaboração de meios jurídicos para garantir a proteção dos bens culturais ameaçados pela industrialização e pela urbanização. De acordo com Barbalho (2007, p.40), do período governamental de Vargas em diante procurou-se construir um sentimento de "brasilidade", “[...] reunindo a dispersa população em torno de ideias comuns, e elaborar uma nova visão do homem brasileiro".

Neste contexto, mediante intensas relações de poder, gradualmente cultura e política foram sendo articulados para a fabricação de uma nação (BARBALHO, 2007). As ações educativas escolares desenvolvidas no período estavam articuladas com estes propósitos (SCHWARTZMAN; BONEMY; COSTA, 2000). Destacava-se a defesa do Barroco enquanto expressão cultural do país e, neste sentido, poucas foram as ações educativas (e estas focadas na unidade nacional). O período, conhecido como "pedra e cal" (DELGADO, 2008), apresenta um discurso de propósitos fundamentais em referência ao coletivo, de caráter nacionalista. São construções de narrativas, de memória e de identidade em que a sociedade deveria apropriar-se, tomando como seu a própria história, seus heróis e seus grandes feitos.

Segundo Hilsdorf (2011), seria possível ampliarmos esse entendimento de nacionalização das ações educativas no Brasil. Embora, de fato, a Era Vargas e a gestão do ministro Gustavo Capanema tenham intensificado o interesse pela homogeneização cultural (SCHWARTZMAN; BONEMY; COSTA, 2000), não podemos desconsiderar que tal nacionalização foi um movimento histórico estendido ao longo do século XX. Teria iniciado com a Liga de Defesa Nacional, com Olavo Bilac em 1916, e se 
projetado por diversos outros momentos da história educacional do país (HILSDORF, 2011).

Os processos escolares, na sequência histórica, passam a valorizar o Brasil, enquanto uma representação homogênea e integrada de identidade nacional. Pelas reformas educacionais das décadas de 1930 e 1940, o ensino de história e geografia do Brasil seria ensinado no primário, assim como os símbolos da pátria, a moral, o civismo e a história dos grandes nomes e "grandes feitos". Há, como vemos, uma valorização da unidade nacional e da homogeneidade cultural, anulando ou inferiorizando outros grupos sociais, caso dos indígenas, por exemplo ${ }^{3}$ (OLIVEIRA, 2003). Nesta conjuntura, ainda não se falava em educação patrimonial pela nomenclatura atual, porém já estava em jogo uma forte relação entre educação e patrimônio nacional.

A educação patrimonial surge em meio às discussões sobre a necessidade de se aprofundar o conhecimento, a conscientização e a preservação do patrimônio histórico e cultural. As primeiras ações designadas como educação patrimonial foram aplicadas no país desde o "I Seminário de Uso Educacional de Museus e Monumentos", ocorrido em 1983 no Museu Imperial no Rio de Janeiro, a partir da tradução do termo anglófono Heritage Education. Desde então, a educação patrimonial assumiu um lugar de metodologia para o desenvolvimento de atividades pedagógicas na escola e em outros espaços sociais. A necessidade de utilizar os "bens culturais como fonte primária de ensino" contribui para a conservação da memória e formação cidadão e torna-se, pela visão institucional, indispensável trabalhar junto com o professor. No ano de 1999, foi publicado o "Guia Básico da Educação Patrimonial” para subsidiar os debates, os estudos e as práticas sobre essa temática. Na ocasião, educação patrimonial foi definida como

[...] um instrumento de 'alfabetização cultural' que possibilita ao indivíduo fazer a leitura do mundo que o rodeia, levando-o à compreensão do universo sociocultural e da trajetória históricotemporal em que está inserido. Este processo leva ao reforço da autoestima dos indivíduos e comunidades e à valorização da cultura brasileira, compreendida como múltipla e plural. (HORTA; GRUNBERG; MONTEIRO, 1999, p. 6).

Ao longo das décadas seguintes, a representação eurocêntrica de patrimônio foi hegemônica. Apenas no fim da década de 1980 esta situação começaria a mudar. Em

${ }^{3}$ Oliveira (2003) evidencia os modos inferiorizados com que os indígenas foram, ao longo da História da Educação Brasileira, inferiorizados ou invisibilizados em livros e manuais didáticos. 
1986, ocorreu o tombamento do terreiro de Casa Branca, em Salvador, foi um reconhecimento da cultura afro-brasileira. Em 1987, houve o tombamento do casario oriundo da imigração italiana em Antônio Prado, o primeiro tombamento material de origem não-portuguesa. Ou, ainda, em 2000, pelo Decreto 3551, foi instituído o Registro de Bens de Natureza Imaterial, caso do Círio de Nazaré, em Belém, ou a arte gráfica kusiwa dos povos indígenas Waiãpi, do Amapá. Com isso, temos observado uma diversificação nas formas da política patrimonial e de educação patrimonial brasileira. Vejamos, na seção a seguir, como esta diversidade cultural acompanha e parece modificar os sentidos da educação patrimonial no país.

\section{EDUCAÇÃO, DIVERSIDADE E PATRIMÔNIO}

Segundo Barbalho, a partir da chegada de Lula à Presidência da República e, com ele, Gilberto Gil ao Ministério da Cultura, ocorreu uma reorientação das ações governamentais em cultura. Segundo o analista, “a preocupação da gestão Gilberto Gil está em revelar os brasis, trabalhar com as múltiplas manifestações culturais, em suas variadas matrizes étnicas, religiosas, de gênero, regionais, etc.” (BARBALHO, 2007, p.52). Essa diretriz representou um esforço pela incorporação nos campos de intervenção da política de atores antes excluídos ou desconsiderados das preocupações governamentais em cultura, patrimônio ou educação. Desta forma, isso significou um interesse pelo reconhecimento oficial de que "[...] a característica marcante de nossa cultura é a riqueza de sua diversidade, resultado de nosso processo histórico-social e das dimensões continentais de nossa territorialidade.” (FERNANDES, 2005, p. 379).

Para aprofundarmos um pouco este debate, precisamos pensar a diversidade cultural antes (ou além) desta preocupação de inclusão social explicitada na gestão de Gilberto Gil. Desde a Declaração Universal dos Direitos Humanos, em 1948, a Organização das Nações Unidas (ONU) passou a manifestar preocupações quanto à "dignidade igualitária de direitos" (CORTÊS, 2012, p. 141). Entretanto, por fatores econômicos, políticos e de relações internacionais, tais posições não mantiveram estabilidade, principalmente quando estão em jogo interesses imperialistas.

A partir de 1970, a UNESCO passou a emitir, com frequência, documentos normatizadores ou orientadores quanto à diversidade cultural. Ao mesmo tempo, diversos movimentos sociais passaram a questionar relações de dominação econômica e cultural sofridas por diversos indivíduos e coletividades, principalmente de mulheres, 
indígenas e trabalhadores rurais. Em 2001, ocorre a publicação da Declaração Universal sobre a Diversidade Cultural, documento no qual a Unesco enfatiza a proposta de "uma nova ética" para o século XXI e a formulação de uma "ferramenta de humanização".

Aqui, nos parece, mais uma vez acompanhando a reflexão de Clélia Cortês, que há pontos importantes de problematização, a saber: como se constituíram políticas para a invisibilidade e exclusão da diversidade cultural nos contextos nacionais diante de acordos internacionais a favor da diversidade? Até que ponto o debate internacional sobre diversidade cultural influenciou os debates nacionais? Desta questão, dois apontamentos parecem pertinentes. Primeiro, que não podemos crer em uma definição universal de diversidade cultural. Os debates inerentes aos organismos internacionais parecem trazer contradições entre um "humanismo global" e os interesses econômicos capitalistas. Segundo, nas escalas políticas nacionais, esta diversidade cultural traduziuse em políticas públicas com diversas orientações.

Atualmente, no Brasil, patrimônio cultural não se limita apenas aos objetos históricos ou artísticos, a monumentos nacionais ou aos centros históricos. Ampliou-se o conceito de patrimônio (CANCLINI, 1994). Porém, nos contextos escolares, tal diversidade cultural ainda não consegue consolidar-se enquanto temática política e pedagógica, argumento este que consiste em um tensionamento ao ingresso da educação patrimonial nas políticas e nas práticas escolares. Neste aspecto, é pertinente a observação de José Ricardo Oriá Fernandes (2005, p.379):

\footnotetext{
Apesar desse fato incontestável de que somos, em virtude de nossa formação histórico-social, uma nação multirracial e pluriétnica, de notável diversidade cultural, a escola brasileira ainda não aprendeu a conviver com essa realidade e, por conseguinte, não sabe trabalhar com as crianças e jovens dos estratos sociais mais pobres, constituídos, na sua grande maioria, de negros e mestiços.
}

Há nos documentos oficiais o reconhecimento da diversidade cultural brasileira, tendo em vista uma relativa abertura nas definições de patrimônio, os quais vêm incorporando novas definições oriundas das Ciências Humanas. Mas, como tal diversidade é associada à educação patrimonial? Como é integrada nos programas políticos para a educação brasileira na atualidade? 


\section{EDUCAÇÃO PATRIMONIAL NO PROGRAMA MAIS EDUCAÇÃO}

O Programa Mais Educação é uma política do Ministério da Educação dirigida à progressiva ampliação da jornada escolar no ensino fundamental. É parte do Plano de Desenvolvimento da Educação (PDE) e configura uma política indutora de educação integral (BRASIL, 2009), além de ser concebido para duas outras finalidades: o enfrentamento das desigualdades sociais e educacionais e a qualificação das escolas públicas brasileiras.

Primeiramente, importa observarmos que parece ser uma prerrogativa deste programa o diálogo com os sujeitos e conhecimentos oriundos das culturas populares. $\mathrm{O}$ Texto Referência Para o Debate Nacional, documento base dessa política, enfatiza que:

Toda a escola está situada em uma comunidade com especificidades culturais, saberes, valores, práticas e crenças - o desafio é reconhecer a legitimidade das condições culturais da comunidade para estimular o diálogo constante com outras culturas. A educação é um dos ambientes da cultura marcada pela reconstrução de conhecimentos, tecnologias, saberes e práticas. (BRASIL, 2009, p. 32).

Nos primeiros cinco anos do programa, o macrocampo que abordava as questões artísticas e culturais se chamava "Cultura e Artes". Em 2012, passou a denominar-se "Cultura, Artes e Educação Patrimonial". A principal mudança foi a ênfase no patrimônio cultural brasileiro, em suas dimensões educativas, socioculturais ou de educação patrimonial. A ementa do referido macrocampo é elucidativa:

Incentivo à produção artística e cultural, individual e coletiva dos estudantes como possibilidade de reconhecimento e recreação estética de si e do mundo, bem como da valorização às questões do patrimônio material e imaterial, produzido historicamente pela humanidade, no sentido de garantir processos de pertencimentos ao local e à sua história. (BRASIL, 2012a, p. 17).

Além de orientar os sentidos deste macrocampo, educação patrimonial é também prevista como uma oficina. O objetivo de tal oficina dialoga com as múltiplas culturas presentes no território brasileiro, uma vez que busca "[...] promover ações educativas para a identificação de referências culturais e fortalecimento dos vínculos das comunidades com seu patrimônio cultural e natural, com a perspectiva de ampliar o entendimento sobre a diversidade cultural [...]" (BRASIL, 2012a, p. 18).

Como é possível observarmos, na perspectiva documental, a diversidade cultural tornou-se temática central à educação patrimonial no Brasil. Resta ainda 
problematizarmos quais sentidos são atribuídos a tal diversidade no Programa Mais Educação. A partir de agora, apresentaremos uma análise sobre o documento Educação Patrimonial para o Programa Mais Educação (BRASIL, 2012b). Este documento é um breve manual endereçado a monitores, professores, coordenadores pedagógicos e gestores envolvidos no Programa Mais Educação. Em suas 19 páginas, mobiliza definições de patrimônio, educação patrimonial e inventário de referências culturais, procurando traduzir para uma linguagem didática um vocabulário mais técnico empregado, principalmente, pelos órgãos oficiais de patrimônio. Tal como em sua ementa e na descrição de seu macrocampo acima expostos, o texto enfatiza a diversidade cultural brasileira, não somente em seus aspectos textuais, mas nas ilustrações presentes em suas páginas. Cada página expõe gravuras de diversas manifestações culturais do país, dentre estas: o frevo, a capoeira, o artesanato, os mercados populares, etc. O documento inicia com a afirmação de que é o patrimônio que faz o Brasil ser Brasil.

Na sequência, analisaremos dois modos pelos quais a diversidade cultural tem sido apresentada e discutida no âmbito do documento em questão, produzindo sentidos à educação patrimonial.

a) Educação patrimonial e o reconhecimento de indivíduos e grupos antes silenciados pela política

Como abordamos anteriormente, as relações entre educação e patrimônio cultural, ao longo da história da educação brasileira no século passado, reforçaram a ideia de síntese (BARBALHO, 2007; BOLÍVAR, 2004). A educação para o patrimônio assumiu características nacionalistas de defesa do patrimônio nacional, da integração social e da homogeneidade cultural. Patrimônio era aquele de pedra e cal (DELGADO, 2008), remanescente da colonização europeia. Nos termos de Pollak, as primeiras ações em educação patrimonial 'silenciavam' diversos indivíduos e grupos sociais brasileiros, sobretudo as populações indígenas e afro-brasileiras. Tais povos não estavam presentes na agenda política educacional, tendência esta verificada em toda a América Latina (CANCLINI, 1994; ZAMBRANO, 2000; DOMÍNGUEZ, 2013). Ao menos no plano documental, nos parece que a inserção da educação patrimonial como temática do Programa Mais Educação adianta neste aspecto. Vejamos sua definição de educação patrimonial: 
A educação patrimonial no Mais Educação propõe uma forma dinâmica e criativa da escola se relacionar com o patrimônio cultural de sua região e, a partir dessa ação, ampliar o entendimento dos vários aspectos que constituem o nosso patrimônio cultural e que isso tem a ver com a formação de cidadania, identidade cultural, memória e outras tantas coisas que fazem parte da nossa vida mas, muitas vezes, não nos damos conta do quão importante elas são. (BRASIL, 2012b, p.4).

A definição acima nos permite visualizar uma proposta educativa que relaciona

educação escolar e patrimônio cultural, de modo plural. De certo modo, aponta para uma desnaturalização da ideia de patrimônio, esta já consagrada e constantemente associada a uma cultura de elite. Ao ampliar os sentidos de patrimônio, sugere que o estudante e o professor possam considerar sua comunidade, sua comunidade escolar, seu município, como elementos pertinentes para uma reflexão sobre suas identidades e para a construção da cidadania no cotidiano das instituições de ensino. O fragmento acima também permite que identifiquemos uma ampliação do conceito de patrimônio nacional, tal como pensado por Néstor Canclini sobre as culturas populares mexicanas.

Ao reconhecer a possibilidade de a própria comunidade ser concebida como patrimônio cultural, o documento ministerial sinaliza para uma rediscussão dos espaços educativos.

Todo espaço que possibilite e estimule, positivamente, o desenvolvimento e as experiências do viver, do conviver, do pensar e do agir consequente [...] Portanto, qualquer espaço pode se tornar um espaço educativo, desde que um grupo de pessoas dele se aproprie, dando-lhe este caráter positivo, tirando-lhe o caráter negativo da passividade e transformando-o num instrumento ativo e dinâmico da ação de seus participantes, mesmo que seja para usá-lo como exemplo crítico de uma realidade que deveria ser outra. (BRASIL, 2012b, p. 7).

Essa discussão traz em si a importância dos espaços não-escolares na formação dos estudantes. O documento reconhece que há aprendizados fundamentais que os estudantes constroem em espaços informais de educação. Isso implica "identificar os contextos culturais das pessoas como importante espaço de formação dos sujeitos" (BRASIL, 2012b, p. 9). Esta percepção tem sido identificada em outras políticas, caso do Programa Cultura Viva e do Programa Mais Cultura nas Escolas (SILVA, 2013).

b) Educação patrimonial como forma de pesquisa da diversidade cultural presente na comunidade escolar 
Se a categoria anterior enfatizava mudanças de sentido no conteúdo da educação patrimonial, esta acentua suas mudanças no método. O documento explora, sobretudo em sua segunda metade, a educação patrimonial como forma de pesquisa da diversidade cultural presente na própria comunidade escolar, a partir da ideia de inventário. Assim,

Fazer um inventário é fazer um levantamento, uma lista descrevendo os bens que pertencem a uma pessoa ou a um grupo. Quando falamos em inventariar os bens culturais de um lugar ou de um grupo social, estamos falando em identificar suas referências culturais. (BRASIL, 2012b, p. 11).

Como o documento foi elaborado em interlocução com o IPHAN, a ideia de inventário foi inspirada nas práticas realizadas por esta entidade. O documento projeta a possibilidade de os estudantes tornarem-se pesquisadores da história, da memória e do patrimônio das comunidades onde residem. Nesse aspecto, difere consideravelmente das definições de educação escolar mais consagradas no país, em particular na Era Vargas, quando os estudantes passaram a reproduzir versões oficiais da História e da Geografia nacional (HILSDORF, 2011). Difere também do entendimento estritamente metodológico atribuído à educação patrimonial no começo dos anos de 1990, quando educação patrimonial acabou por assumir uma ênfase na conscientização dos estudantes para a salvaguarda das memórias e dos patrimônios.

$\mathrm{Na}$ ótica do documento, as referências culturais da comunidade são levadas para dentro das salas de aula, visando perscrutar, no contexto da escola, elementos sociais e simbólicos que definem as referências de significação para aquela comunidade. $O$ documento oficial ainda acrescenta que cinco seriam as referências culturais a inventariar na comunidade escolar, a saber: lugares, objetos, celebrações, formas de expressão e saberes.

Do ponto de vista historiográfico, esse entendimento acrescenta à pesquisa das referências culturais a necessidade de ir além da história oficial, pesquisando as histórias dos lugares onde vivem e das pessoas com as quais convivem. Nos termos do sociólogo Michael Pollak, tal metodologia permite a busca "das memórias subterrâneas" - aquelas que foram silenciadas ou tornaram-se pouco perceptíveis pela memória oficial.

Ao indicar a proposta educativa presente na inserção da educação patrimonial no Programa Mais Educação, o documento ainda explicita que "a proposta da Educação Patrimonial na escola é envolver a comunidade escolar no reconhecimento e valorização 
dos bens culturais e das pessoas que formam o patrimônio cultural, e que estão bem ao nosso lado (BRASIL, 2012b, p. 10).

\section{CONSIDERAÇÕES FINAIS}

Neste artigo, em específico, identificamos a emergência da diversidade cultural na pauta das políticas educacionais e, em especial, na educação patrimonial. Procedemos a um estudo bibliográfico e uma análise documental a fim de compreendermos os sentidos presentes na inserção da educação patrimonial no Programa Mais Educação. Interrogamo-nos pelas formas com que a diversidade cultural foi modificando a pauta da educação patrimonial e, de certo modo, realizando deslocamentos em seus sentidos. Da homogeneidade para a diversidade cultural. Porém, tal abertura ao debate é fundamental, mas apenas o primeiro passo, pois “[...] la coexistência o simples convivencia de culturas no expresa necesariamente la condición multicultural [...]" (DOMÍNGUEZ, 2013, p. 71), tampouco a efetiva democratização cultural (SILVA, 2013). Como observa Zambrano (2000, p. 149):

El reconocimiento de la diversidad cultural en América Latina
modifica la percepción sobre su propia realidad social y cultural. La
transformación de dicha percepción es fuente, parte y resultado de un
cambio progresivo y conflictivo, que se desenvuelve de una manera
compleja y multidimensional, con implicaciones no solo sobre los
sujetos que incorpora sino sobre la redefinición de sociedad en su
conjunto. En la presente década algunos frutos del reconocimiento de
la diversidad cultural saltan a la vista en forma de adecuaciones
institucionales, reformas jurídicas, definición de políticas,
elaboración de presupuestos y surgimiento de nuevas organizaciones
yactores sociales.

Ao analisarmos o documento "Educação Patrimonial para o Programa Mais Educação" (BRASIL, 2012b), além de outros materiais, constatamos que a educação patrimonial mobiliza dois sentidos para a diversidade cultural. Certamente são dois aqueles que nosso olhar conseguiu perceber nesse momento. Assim, após esta breve análise, constatamos que "educação patrimonial e o reconhecimento de indivíduos e grupos antes silenciados pela política" e "educação patrimonial como forma de pesquisa da diversidade cultural presente na diversidade cultural" seriam categorias que, minimamente, responderiam nossas interrogações sobre os sentidos de diversidade cultural na educação patrimonial brasileira. 


\section{HERITAGE, CULTURAL DIVERSITY AND EDUCATION SCHOOL: EDUCATION IN PROGRAMA MAIS EDUCAÇÃO ON HERITAGE}

ABSTRACT: This article aims to understand the relationship between heritage education and cultural diversity in Brazilian educational politics, with emphasis on analysis of ministerial documents that belong to heritage education as a theme in Programa Mais Educação. The authors analyze two shifts in the production of sense historically attributed to heritage education and its relationship with contemporary schooling processes.

KEYWORDS: Heritage education. Cultural diversity. Educational policy.

\section{REFERÊNCIAS}

BARBALHO, A. Políticas culturais no Brasil: identidade e diversidade sem diferença. In: RUBIM, A. A. (Org.). Políticas culturais no Brasil. Salvador: Ed. da UFBA, 2007. p.37-60.

BOLÍVAR, A. Ciudadanía y escuela publica en el contexto de diversidad cultural.

Revista Mexicana de Investigación Educativa, México, n. 20, v. 9, p. 15-38, jan./abr. 2004.

BRASIL. Ministério da Educação. Manual operacional de educação integral. Brasília, 2012a.

Educação patrimonial para o programa mais educação. Brasília, 2012 b.

Educação integral: texto referência para o debate nacional. Brasília, 2009.

Decreto-Lei $n^{\circ} 25$, de 30 de novembro de 1937. Organiza a proteção do patrimônio histórico e artístico nacional. Diário Oficial da União, Brasília, DF, 06 dez. 1937. Disponível em: <http://www.planalto.gov.br/ccivil_03/Decreto-

Lei/Del0025.htm>. Acesso em: 20 dez. 2015.

CANCLINI, N. G. O patrimônio cultural e a construção imaginária do nacional.

Revista do Patrimônio Histórico e Artístico Nacional, Brasília, n. 23, p. 95-115, 1994.

CANDAU, V. Ser professor/a hoje: novos confrontos entre saberes, culturas e práticas. Educação, Porto Alegre, v. 37, n. 1, p. 33-41, jan./abr. 2014.

CORTÊS, C. Cultura, diversidade e política: transversalidade dos conceitos nas políticas culturais. In: RUBIM, A. A. C.; ROCHA, R. (Org.). Políticas culturais. Salvador: Ed. da UFBA, 2012. p. 139-159

DELGADO, A. F. Configurações do campo do patrimônio no Brasil. In: BARRETO, E. et al. (Org.). Patrimônio cultural e educação: artigos e resultados. Goiânia: Ed. Da UFG, 2008. p. 97-112 
DOMINGUEZ, J. B. Educación intercultural: ¿trabajar con los diferentes o las diferencias? Revista Ra Ximhai, México, v. 9, n. 1, p. 61-73, jan./abr. 2013.

La educación en el contexto de la diversidad. Educação em foco, Juiz de Fora, v. 17, n. 1, p. 21-42, mar./jun. 2012.

FERNANDES, J. R. O. Ensino de História e diversidade cultural: desafios e possibilidades. Cadernos Cedes, Campinas, v. 25, n. 67, p. 378-388, set./dez. 2005.

HILSDORF, M. L. História da educação brasileira: leituras. São Paulo: Cengage Learning, 2011.

HORTA, M. L.; GRUNBERG, E.; MONTEIRO, A. Guia básico de educação patrimonial. Brasília: IPHAN, 1999.

MARTÍN-BARBERO, J. Dos meios às mediações: comunicação, cultura e hegemonia. 6. ed. Rio de Janeiro: Ed. da UFRJ, 2009.

OLIVEIRA, T. S. Olhares que fazem a diferença: o índio em livros didáticos e outros artefatos culturais. Revista Brasileira de Educação, Rio de Janeiro, n. 22, p.25-34, jan./abr. 2003.

POLLAK, M. Memória, esquecimento, silêncio. Estudos Históricos, Rio de Janeiro, v.2, n. 3, p. 3-15, jan. 1989.

SCHWARTZMAN, S.; BONEMY, H.; COSTA, V. M. Tempos de Capanema. São Paulo: Paz e Terra, 2000.

SILVA, R. M. D. Narrativas de democratização cultural no Brasil: um olhar sociológico ao Programa Cultura Viva. Revista Ciências Sociais Unisinos, São Leopoldo, v. 49, n.3, p. 269-278, set./dez. 2013.

Os direitos culturais e a política educacional brasileira na contemporaneidade.

Revista Brasileira de Política e Administração da Educação, Porto Alegre, v. 26, n.1, p. 123-136, jan./abr. 2010.

ZAMBRANO, C. Diversidad cultural ampliada y educación para la diversidad. Nueva sociedad, Buenos Aires, n. 165, p. 148-159, 2000.

\section{BIBLIOGRAFIA CONSULTADA}

CALABRE, L. Políticas culturais no Brasil: dos anos de 1930 ao século XXI. Rio de Janeiro: Fundação Getúlio Vargas, 2009.

CAVALIERE, A. M. Educação integral: uma nova identidade para a escola brasileira? Educação \& Sociedade, Campinas, v. 23, n. 81, p. 247-270, dez. 2002. 
GRUNBERG, E. Educação patrimonial: utilização dos bens culturais como recursos educacionais. Disponível em:

<http://www.pead.faced.ufrgs.br/sites/publico/eixo4_tutores/estudos_sociais/materiais/e ducacao_patrimonial.pdf >. Acesso em: 10 set. 2013.

HALL, S. Identidade cultural na pós-modernidade. Rio de Janeiro: DP\&A, 2007.

LONDRES, C. O Patrimônio cultural na formação das novas gerações: algumas considerações. In: TOLENTINO, A. B. (Org.). Educação patrimonial: reflexões e práticas. João Pessoa: Superintendência do IPHAN na Paraíba, 2012. p.14-21.

35 REIS, M. Uma nova leitura da função social da escola no processo de formação da nação na América Latina. Sociedade e Estado, Brasília, v. 14, n. 2, p. 369-390, jul./dez. 1999. 